\title{
Synthesis of 1-(pyridyl, quinolyl, and isoquinolyl)azulenes by Reissert-Henze type reaction
}

\author{
Taku Shoji, ${ }^{a *}$ Kazuyuki Okada, ${ }^{b}$ Shunji Ito, ${ }^{c}$ Kozo Toyota, ${ }^{b}$ and Noboru Morita ${ }^{b}$ \\ ${ }^{a}$ Department of Chemistry, Faculty of Science, Shinshu University, Matsumoto 390-8621, Japan \\ ${ }^{b}$ Department of Chemistry, Graduate School of Science, Tohoku University, Sendai 980-8578, Japan \\ ${ }^{c}$ Graduate School of Science and Technology, Hirosaki University, Hirosaki 036-8561, Japan
}

\begin{abstract}
Azulene derivatives reacted with $N$-oxide of several heterocycles in the presence of trifluoromethanesulfonic anhydride $\left(\mathrm{Tf}_{2} \mathrm{O}\right)$ to afford 1-(pyridyl, quinolyl and isoquinolyl)azulenes in good yield, respectively. In the case of the reaction with the 1-azulenyl methyl sulfide (12), 1,1'-biazulene derivative 13 was obtained under the similar reaction conditions. The first synthesis of unsymmetrical 1,3di(pyridyl)azulene derivative was also established via our new preparation method following the electrophilic pyridinylation using the reaction with pyridine in the presence of $\mathrm{Tf}_{2} \mathrm{O}$. (C) 2012 Elsevier Science. All rights reserved
\end{abstract}

$\mathrm{N}$-Containing heterocycles are very important compounds from the viewpoint of material and pharmaceutical chemistries. 1 Therefore, the methods for their functionalization were extensively studied by many research groups. Recently, Fangou et al. reported the transition metalcatalyzed directive functionalization of the $N$-containing heterocycles utilizing their $N$-oxides, such as arylation and vinylation. $^{2}$ Their methodologies provide a facile and an efficient synthetic route to polyfunctionalized heterocycles.

Reissert-Henze (R-H) type reaction is one of the other possibility for the functionalization of the $N$-containing heterocycles, ${ }^{3}$ because the $N$-containing heterocycles cause some difficulties owing to their less reactivities toward the electrophilic substitution reactions. However, the most of the examples for the functionalization by the $\mathrm{R}-\mathrm{H}$ type reaction were limited, so far, to such as cyanation, ${ }^{1 \mathrm{c}}$ alkylation, ${ }^{4}$ and amination. ${ }^{5}$ In 1967, Hamana and Kumadaki reported a direct heteroarylation of indole via the $\mathrm{R}-\mathrm{H}$ type electrophilic reaction. ${ }^{6}$ However, there is still few report for the R-H type heteroarylation of aromatic compounds, except for those of the indole derivatives.

Azulene $\left(\mathrm{C}_{10} \mathrm{H}_{8}\right)$ has attracted the interest of many research groups due to its unusual properties as well as its beautiful blue color. ${ }^{7}$ We have recently reported the synthesis of several arylazulene derivatives by the transition metal-catalyzed cross-coupling reactions. ${ }^{8}$ However, although many transition metal-catalyzed aryl-aryl coupling are developed, synthesis of 1 -arylazulenes by utilizing the transition metal-catalyzed reaction might be difficult because of the low stability of 1haloazulenes required. Moreover, preparation of the metal reagents for the coupling reaction is not easy for 1-azulenyl derivatives and the most promising 1-azulenylborane reagent is cause easy hydrolysis to afford hydrocarbon derivative. ${ }^{9}$ Recently, Oda et al. reported efficient Suzuki-Miyaura and Stille coupling reactions of 1-halo- and 1,3-dihaloazulenes. ${ }^{10}$ However, the procedures require either existence of an electron-withdrawing group on azulene ring at the 3-position or excess amount of aryl boran or tin reagents. Wakabayashi et al. also reported the palladium-mediated synthesis of several pyridylazulene derivatives, and these compounds behaved as a detector for acid and metal-ions. ${ }^{11}$

More recently, we have demonstrated a new and two-step strategy for the heteroarylation of azulenes at the 1-, 1,3-, 5-, and 5,7-positions by the reaction with the triflate of $N$ containing heterocycles. ${ }^{12}$ The triflate of $\mathrm{N}$-containing heterocycles is readily available from the reaction of the corresponding $\mathrm{N}$-containing heterocycles with trifluoromethanesulfonic anhydride $\left(\mathrm{Tf}_{2} \mathrm{O}\right)$. The reaction of azulene derivatives with the triflates gives the corresponding dihydroheteroarylazulenes, which are easily transformed to the corresponding heteroarylazulenes by the base treatment.

The success of the two-step synthesis of the heteroarylazulenes encouraged us to develop a directive heteroarylation methodology of azulene derivatives using the R-H type electrophilic reaction. As the results, a directive synthetic route to the heteroarylazulenes could be

Keywords: Azulene; Heterocycle; Electrophilic arylation.

* Corresponding authors. Tel.and Fax: +81-263-37-2476; e-mail: tshoji@shinshu-u.ac.jp 
opened by the $N$-oxide of several $N$-containing heterocycles with azulenes utilizing the R-H type electrophilic arylation.

We report herein the R-H type electrophilic arylation of $N$-containing heterocycles with azulenes, particularly, the application of this methodology to the unsymmetrical 1,3di(pyridyl)azulene by the combination with our two-step procedure starting from the reaction with triflate of pyridine reported previously.

As a preliminary experiment, the reaction of azulene (1) with pyridine $\mathrm{N}$-oxide as a model substrate was examined in a presence of variety of activating reagents (Scheme 1, Table 1). The reaction of 1 with pyridine $\mathrm{N}$-oxide in the presence of $\mathrm{Tf}_{2} \mathrm{O}$ afforded 1-(2-pyridyl)azulene (2) in $45 \%$ yield (Table 1, Entry 1). ${ }^{13}$ However, the other activating reagents examined, such as benzoyl chloride and acetic anhydride $\left(\mathrm{Ac}_{2} \mathrm{O}\right)$, did not induce the electrophilic substitution reaction, even though the reaction was carried out under the reflux conditions in acetonitrile (Table 1, Entries 2 and 3). When trifluoroacetic anhydride (TFAA) was used as an activating reagent, 1trifluoroacetylazulene $(3)^{14}$ was obtained in $87 \%$ yield instead of the desired 2 (Table 1, Entry 4, Chart 1).

Recently, we reported that the reaction of 1 with triflate of pyridine prepared with an equimolar amount of $\mathrm{Tf}_{2} \mathrm{O}$ and pyridine gives 6-(1-azulenyl)-1-(trifluoromethylsulfonyl)-1azahexa-1,3,5-triene as the main product by the attack of azulene on pyridine at the 2-position. ${ }^{12 \mathrm{a}}$ Therefore, formation of the 2-pyridyl derivative $\mathbf{2}$ is contrastive results to those of our previous two-step procedure utilizing the reaction with triflate of pyridine, which affords 4-pyridyl derivative, exclusively.

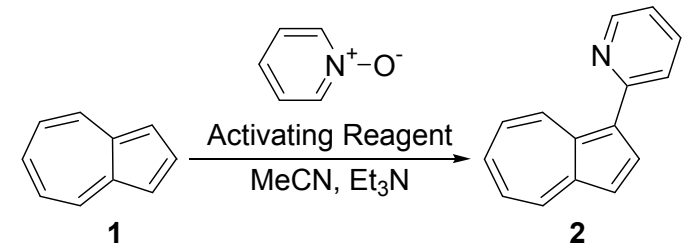

Scheme 1.

Table 1. Synthesis of 1-(2-pyridyl)azulene (2)

\begin{tabular}{llll}
\hline Entry & Activating Reagent & Temperature, ${ }^{\circ} \mathrm{C}$ & Yield, $\%$ \\
\hline 1 & $\mathrm{Tf}_{2} \mathrm{O}$ & r.t. & 45 \\
2 & $\mathrm{PhCOCl}$ & reflux & No reaction \\
3 & $\mathrm{Ac}_{2} \mathrm{O}$ & reflux & No reaction \\
4 & $\mathrm{TFAA}$ & r.t. & 0 \\
\hline
\end{tabular}<smiles></smiles>

Chart 1.

The $\mathrm{Tf}_{2} \mathrm{O}$ activated $\mathrm{R}-\mathrm{H}$ reaction of $\mathbf{1}$ with pyridine $\mathrm{N}$-oxide was examined in three different organic solvents. As summarized in Table 2, yields of the product were significantly depended on the solvent employed. The less polar aromatic solvent, i.e., in benzene, was revealed to be insufficient for the reaction due to the significant decomposition of the compound was observed. Whereas, using the more polar solvent $\mathrm{CH}_{2} \mathrm{Cl}_{2}$, formation of the desired product 2 was observed, but in fairly lower yield $(6 \%)$. Among the solvents tested, the highly polar, but aprotic polar solvent, acetonitrile was found to be the best with respect to the yield of the product (45\%).

Table 2. Solvent effect on the Reissert-Henze reaction of 1 with pyridine $\mathrm{N}$-oxide activated by $\mathrm{Tf}_{2} \mathrm{O}$

\begin{tabular}{llll}
\hline Entry & Solvent & Temperature, ${ }^{\circ} \mathrm{C}$ & Yield, $\%$ \\
\hline 1 & $\mathrm{MeCN}_{2}$ & r.t. & 45 \\
2 & $\mathrm{CH}_{2} \mathrm{Cl}_{2}$ & r.t. & 6 \\
3 & Benzene & r.t. & 0 \\
\hline
\end{tabular}

Isoquinoline $\mathrm{N}$-oxide was applied to the reaction under the optimized reaction conditions (Scheme 2). The reaction of 1 with isoquinoline $\mathrm{N}$-oxide in the presence of $\mathrm{Tf}_{2} \mathrm{O}$ afforded 1(2-quinolyl)azulene (4) in 51\% yield (Table 3, Entry 1). It is noteworthy that the reaction could also be activated by benzoyl chloride to give 4 in $44 \%$ yield, although the benzoyloxy group should be less effective leaving-group compared with TfO group (Table 3, Entry 2). However, $\mathrm{Ac}_{2} \mathrm{O}$ was also insufficient for the activation of this reaction and utilization of TFAA as an activating reagent resulted to the formation of 3 in $90 \%$ yield as a same way of the reaction with pyridine $\mathrm{N}$-oxide (Table 3, Entries 3 and 4). These results showed $\mathrm{Tf}_{2} \mathrm{O}$ is the most effective reagent for the activation of $\mathrm{N}$-oxide of $\mathrm{N}$-containing heterocycles and we decide to use it as optimized conditions.

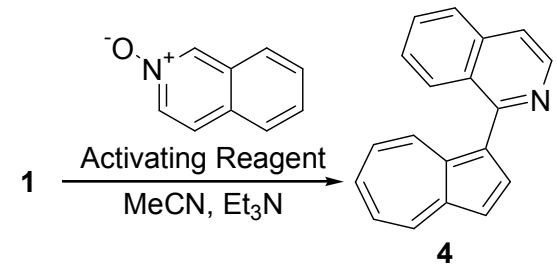

Scheme 2

Table 3. Synthesis of 1-(1-isoquinolyl)azulene (4)

\begin{tabular}{llll}
\hline Entry & Reagent & Temperature, ${ }^{\circ} \mathrm{C}$ & Yield, $\%$ \\
\hline 1 & $\mathrm{Tf}_{2} \mathrm{O}$ & r.t. & 51 \\
2 & $\mathrm{PhCOCl}$ & reflux & 44 \\
3 & $\mathrm{Ac}_{2} \mathrm{O}$ & reflux & No reaction \\
4 & $\mathrm{TFAA}$ & r.t. & 0 \\
\hline
\end{tabular}

To examine the generality of the reaction with the $N$-oxide of heterocycles, we investigated the reaction of $\mathbf{1}$ with three commercially available $N$-oxides under the optimized reaction conditions (Scheme 3 and Chart 2). $N$-Oxides of 4nitropyridine and 3-methylpyridine were reacted with $\mathbf{1}$ in the presence of $\mathrm{Tf}_{2} \mathrm{O}$ to give the corresponding 1-(2pyridyl)azulenes 5 and $\mathbf{6}$ in 28\% and 12\% yields, respectively, but the yields were relatively low (Table 4, Entries 3 and 4). The reaction of 1 with quinoline $N$-oxide gave the presumed 1-(2-quinolyl)azulene (7) in 44\% yield (Table 4, Entry 3). These results show the generality of the $\mathrm{R}-\mathrm{H}$ reaction of azulene with $\mathrm{N}$-oxide of heterocycles. 


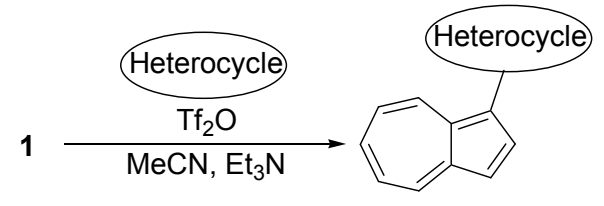

Scheme 3.

Table 4. Synthesis of 1-(pyridyl and quinolyl)azulene derivatives

\begin{tabular}{lll}
\hline Entry & $N$-oxide & Product, Yield (\%) \\
\hline 1 & 4-nitropyridine $N$-oxide & $\mathbf{5 , 2 8}$ \\
2 & 3-methylpyridine $N$-oxide & $\mathbf{6}, 12$ \\
3 & quinoline $N$-oxide & $\mathbf{7 , 4 4}$ \\
\hline
\end{tabular}<smiles>Cc1ccc(-c2ccc3cccccc2-3)nc1</smiles>

Chart 2.

A series of azulene derivatives were subjected to this $\mathrm{R}-\mathrm{H}$ type reaction under the optimized reaction conditions to explore the scope of this reaction (Scheme 4). Examined compounds are shown in Chart 3. The reaction of 1-tertbutylazulene with pyridine $N$-oxide afforded 8 in $60 \%$ yield (Table 5, Entry 1). Lower yield for the reaction of 6-tertbutylazulene with pyridine $N$-oxide is attributable to the instability of the product under the reaction conditions (Table 5, Entry 2). 6-Dimethylamino derivative 10 was also obtained under a similar reaction conditions with 6dimethylaminoazulene in $55 \%$ yield (Table 5, Entry 3 ). However, guaiazulene was inefficient for the reaction resulted in a relatively low yield, because of the instability of the product under the reaction conditions (Table 5, Entry 4).

There are several reports for the synthesis of 1(heteroaryl)azulenes. However, in most cases the methodologies require high temperature reaction or transitionmetal catalysts. In the present method, the reaction could be carried out under mild conditions. Furthermore, electrophilic arylation does not require the modification of azulene ring prior to the reaction, such as halogenation, borylation, or stannylation. Therefore, the electrophilic arylation may also have advantage over the transition metal-catalyzed synthesis of 1-(heteroaryl)azulenes.

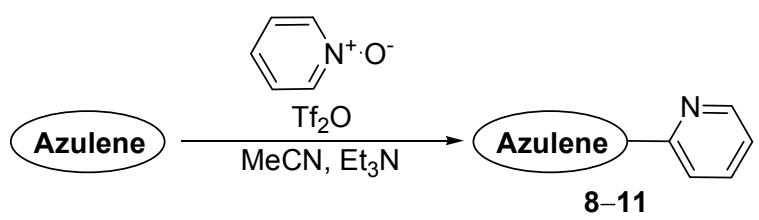

Scheme 4.

Table 5. Synthesis of 1-(pyridyl)azulenes 8-11

\begin{tabular}{lll}
\hline Entry & Azulene & Product, Yield (\%) \\
\hline 1 & 1-tert-butylazulene & $\mathbf{8}, 60$
\end{tabular}

\begin{tabular}{lll}
2 & 6-tert-butylazulene & $\mathbf{9}, 22$ \\
3 & 6-dimethylaminoazulene & $\mathbf{1 0}, 55$ \\
4 & guaiazulene & $\mathbf{1 1}, 30$ \\
\hline
\end{tabular}

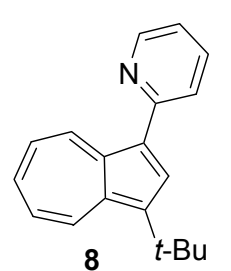<smiles>CC(C)(C)c1ccc2ccc(-c3ccccn3)c-2cc1</smiles><smiles>CN(C)c1ccc2ccc(-c3ccccn3)c-2cc1</smiles>

10<smiles>Cc1cc(-c2ccccn2)cc(C)c1-c1ccccc1</smiles>

Chart 3.

We found 1,1'-biazulene derivative $\mathbf{1 3}$ was obtained by the reaction of 12 with pyridine $N$-oxide in $40 \%$ yield under our reaction conditions (Scheme 5). Several synthetic methodologies of 1,1'-biazulenes have been reported in the literatures. However, in most cases the methodologies require metal-catalyst, high temperature reaction, and/or longer reaction period. ${ }^{15}$ Recently, we have also reported the facile preparation of the 1,1'-biazulene derivative $\mathbf{1 3}$ by the treatment of 1-azulenyl methyl sulfoxide (14) with Brønsted acid as shown in Scheme 5. ${ }^{16}$ Therefore, the formation of $\mathbf{1 3}$ in this reaction might be attributable to the pyridine $N$-oxide, which should act as an oxidant for the generation of $\mathbf{1 4}$. We investigated the reaction of $\mathbf{1 2}$ without $\mathrm{Tf}_{2} \mathrm{O}$, to examine the presumed oxidation reaction with pyridine $\mathrm{N}$-oxide. However, the reaction resulted in the complete recovery of the starting 12. Therefore, $\mathrm{Tf}_{2} \mathrm{O}$ was essential for the oxidation of $\mathbf{1 2}$ to give the 1,1'-biazulene derivative, although the reaction mechanism is unclear.

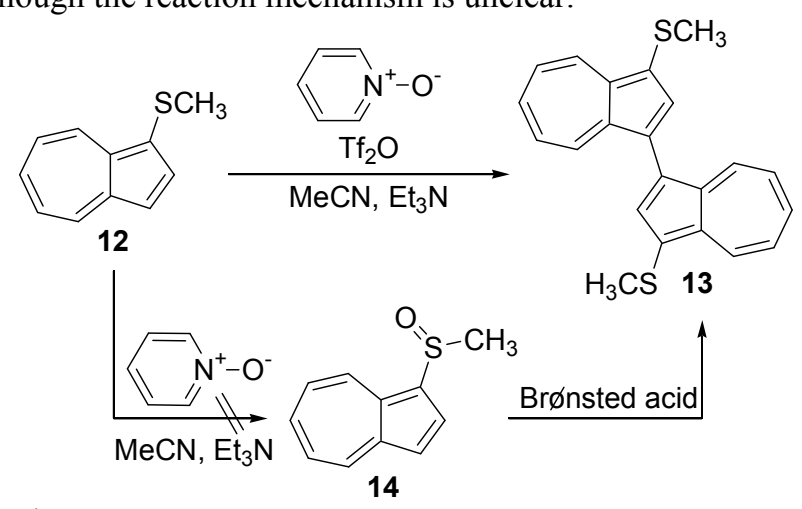

Scheme 5 .

Preparation of symmetrically substituted 1,3di(pyridyl)azulenes have been reported by us and several groups, recently. ${ }^{10 \mathrm{c}, 11,12 \mathrm{~b}}$ In 2008 , Jacquemin et al. reported the spectral calculation and acidochromism of symmetric 1,3bis(2-pyridyl and 4-pyridyl)azulene, and these compounds have a potential to be a new $\mathrm{pH}$ sensor. ${ }^{17}$ However, 
unsymmetrically substituted 1,3-di(pyridyl)azulenes have never been reported so far. To evaluate the applicability of this reaction, we have examined the synthesis of unsymmetrically substituted 1,3-di(pyridyl)azulene $\mathbf{1 5}$ via using our new methodology. ${ }^{12 \mathrm{~b}, \mathrm{~d}}$

Reaction of 2 with pyridine in the presence of $\mathrm{Tf}_{2} \mathrm{O}$ gave 1(4-dihydropyridyl)-3-(2-pyridyl)azulene derivative 15 in 95\% yield. Treatment of the product $\mathbf{1 5}$ with $\mathrm{KOH}$ in ethanol gave the presumed 1-(2-pyridyl)-3-(4-pyridyl)azulene (16) in 58\% yield (Scheme 6).

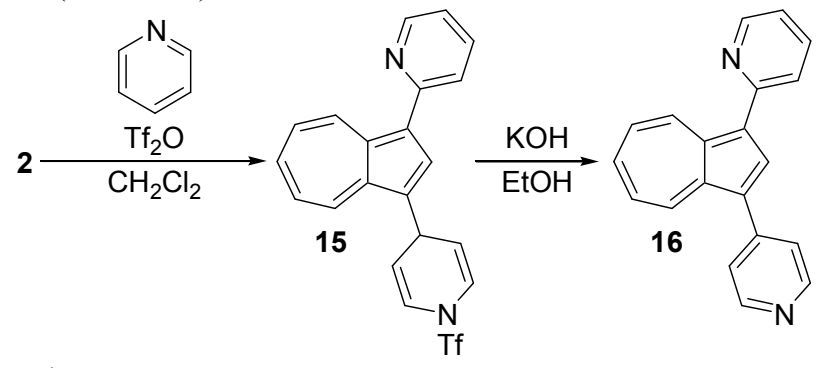

Scheme 6.

In conclusion, the R-H type electrophilic heteroarylation of azulene using the $N$-oxide of several heterocycles with $\mathrm{Tf}_{2} \mathrm{O}$ has been disclosed. Starting from stable and commercially available substrates, this methodology allows us to access to the $\mathrm{N}$-containing 1-(heteroaryl)azulenes that are difficult to obtain by other methods. Formation of the 2-pyridyl derivative $\mathbf{2}$ by the present method should be a compliment of our previous two-step procedure utilizing the reaction with triflate of pyridine, which affords 4-pyridyl derivative, exclusively. In the similar reaction conditions, we found 1azulenyl methyl sulfide (12) was converted into 1,1'-biazulene derivative 13, which may open a novel access method to the 1,1'-biazulene derivatives. Electrophilic pyridynylation of $\mathbf{2}$ by our previous two-step procedure utilizing the reaction with triflate of pyridine, we have established the first synthesis of unsymmetrically substituted 1,3-di(pyridyl)azulene $\mathbf{1 5}$. Physical properties of these new compounds are now under investigation in our laboratory.

\section{Acknowledgement}

This work was partially supported by the global COE project, International Center of Research \& Education for Molecular Complex Chemistry, of the Ministry of Education, Culture, Sports, Science, and Technology, Japan.

\section{Reference}

1. (a) Craig, P. N. In Comprehensive Medicinal Chemistry; Drayton, C. J., Ed.; Pergamon Press: New York, 1991; Vol. 8; (b) Southon, I. W.; Buckingham, J. In Dictionary of Alkaloids; Saxton, J. E., Ed.; Chapman and Hall: London, 1989; (c) Negwer, M. In Organic-Chemical Drugs and their Synonyms: (An International Survey), 7th ed.; Akademie Verlag GmbH: Berlin, 1994.

2. (a) Campeau, L.-C.; Rousseaux, S.; Fagnou, K. J. Am. Chem. Soc. 2005, 127, 18020-18021; (b) Leclerc, J.-P.; Fagnou, K. Angew. Chem. Int. Ed. 2006, 45, 7781-7786; (c) Campeau, L-. C.; Schipper, D.-J.; Fagnou, K. J. Am. Chem. Soc. 2008, 130,
3266-3267; (d) Campeau, L.-C.; Bertrand-Laperle, M.; Leclerc, J.-P.; Villemure, E.; Gorelsky, S.; Fagnou, K. J. Am. Chem. Soc. 2008, 130, 3276-3277; (e) Campeau, L.-C.; Stuart, D.-R.; Leclerc, J.-P.; Bertrand-Laperle, M.; Villemure, E.; Sun, H.-Y.; Lasserre, S.; Guimond, N.; Lecavallier, M.; Fagnou, K. J. Am. Chem. Soc. 2009, 131, 3291-3306; (f) Schipper, D.-J.; Campeau, L.-C.; Fagnou, K. Tetrahedron 2009, 65, 31553164; (g) Schipper, D.-J.; El-Salfiti, M.; Whipp, C.-J.; Fagnou, K. Tetrahedron 2009, 65, 4977-4983.

3. (a) Reissert, A. Chem. Ber. 1905, 38, 1603-1614; (b) Reissert, A. Chem. Ber. 1905, 38, 3415-3435; (c) Hanze, M. Chem. Ber. 1936, 69, 1566-1568; (d) McEwen, W. E.; Cobb, R. L. Chem. Rev. 1955, 55, 511-549.

4. (a) Doering, W. E.; McEwen, W. E. J. Am. Chem. Soc. 1951, 73, 2104-2109; (b) Hamana, M.; Yamazaki, M. Chem. Pharm. Bull. 1963, 11, 415-421; (c) Hamana, M.; Noda, H. Chem. Pharm. Bull. 1963, 11, 1331-1333; (d) Hamana, M.; Noda, H. Chem. Pharm. Bull. 1965, 13, 912-920; (e) Baty, J. D.; Jones, G.; Moore, C. J. Org. Chem. 1969, 34, 3295-3302.

5. Hamana, M.; Hoshino, O. Yakugaku Zasshi, 1969, 89, 641-644.

6. Hamana, M.; Kumadaki, I. Chem. Pharm. Bull. 1967, 15, 363366.

7. Zeller, K.-P. Azulene. In Houben-Weyl; Methoden der Organischen Chemie, 4th ed.; Kropf, H. Ed.; Georg Thieme: Stuttgart, Germany, 1985; Vol. V, Part 2c, pp 127-418.

8. (a) Ito, S.; Inabe, H.; Okujima, T.; Morita, N.; Watanabe, M.; Harada, N.; Imafuku, K. J. Org. Chem. 2001, 66, 7090-7101; (b) Ito, S.; Nomura, A.; Morita, N.; Kabuto, C.; Kobayashi, H.; Maejima, S.; Fujimori, K.; Yasunami, M. J. Org. Chem. 2002, 67, 7295-7302; (c) Ito, S.; Okujima, T.; Morita, N. Tetrahedron Lett. 2002, 43, 1261-1264; (d) Ito, S.; Okujima, T.; Morita, N. J. Chem. Soc., Perkin Trans. 1 2002, 18961905; (e) Ito, S.; Inabe, H.; Morita, N.; Ohta, K.; Kitamura, T.; Imafuku, K. J. Am. Chem. Soc. 2003, 125, 1669-1680; (f) Ito, S.; Terazono, T.; Kubo, T.; Okujima, T.; Morita, N.; Murafuji, T.; Sugihara, Y.; Fujimori, K.; Kawakami, J.; Tajiri, A. Tetrahedron 2004, 59, 5357-5366.

9. Ito, S.; Kubo, T.; Morita, N.; Matsui, Y.; Watanabe, T.; Ohta, A.; Fujimori, K.; Murafuji, T.; Sugihara, Y.; Tajiri, A. Tetrahedron Lett. 2004, 45, 2891-2894.

10. (a) Thanh, N. C.; Ikai, M.; Kajioka, T.; Fujikawa, H.; Taga, Y.; Ogawa, S.; Zhang, T.; Shimada, H.; Miyahara, Y.; Kuroda, S.; Oda, M. Tetrahedron 2006, 62, 11227-11239; (b) Oda, M.; Thanh, N. C.; Ikai, M.; Fujikawa, H.; Nakajima, K.; Kuroda, S. Tetrahedron 2007, 63, 10608-10614; (c) Oda, M.; Kishi, S.; Thanh, N. C.; Kuroda, S. Heterocycles 2007, 71, 1413-1416.

11.Wakabayashi, S.; Kato, Y.; Mochizuki, K.; Suzuki, R.; Matsumoto, M.; Sugihara, Y.; Shimizu, M. J. Org. Chem. 2007, 73, 744-749.

12. (a) Ito, S.; Yokoyama, R.; Okujima, T.; Terazono, T.; Kubo, T.; Tajiri, A.; Watanabe, M.; Morita, N. Org. Biomol. Chem. 2003, 1, 1947-1952; (b) Shoji, T.; Yokoyama, R.; Ito, S.; Watanabe, M.; Toyota, K.; Yasunami, M.; Morita, N. Tetrahedron Lett. 2007, 48, 1099-1103; (c) Shoji, T.; Ito, S.; Watanabe, M.; Toyota, K.; Yasunami, M.; Morita, N. Tetrahedron Lett. 2007, 48, 3009-3012; (d) Higashi, J.; Shoji, T.; Ito, S.; Toyota, K.; Yasunami, M.; Morita, N. Eur. J. Org. Chem. 2008, 5823-5831; (e) Shoji, T.; Ito, S.; Toyota, K.; Morita, N. Eur. J. Org. Chem. 2010, 1059-1069.

13. Typical procedure: Trifluoromethanesulfonic anhydride (931 $\mathrm{mg}, 3.30 \mathrm{mmol})$ was added to a solution of $1(128 \mathrm{mg}, 1.00$ mmol), pyridine $N$-oxide (285 mg, $3.00 \mathrm{mmol})$ and $\mathrm{Et}_{3} \mathrm{~N}(1.01$ $\mathrm{g}, 10.0 \mathrm{mmol})$ in acetonitrile $(20 \mathrm{~mL})$. The resulting solution was stirred at room temperature for $30 \mathrm{~min}$. The reaction mixture was poured into water and extracted with $\mathrm{CHCl}_{3}$, dried with $\mathrm{MgSO}_{4}$, and concentrated under reduced pressure. The 
crude product was purified by column chromatography on silica gel with hexane/AcOEt (10:1) to afford 2 (92 mg, 0.45 mmol) as blue oil.

14. Mathias, L. J.; Overberger. C. G. J. Org. Chem. 1980, 45, 1701-1703.

15. (a) Morita, T.; Takase, K. Bull. Chem. Soc. Jpn. 1982, 55, 1144-1152; (b) Iyoda, M.; Sato, K.; Oda, M. Tetrahedron Lett. 1985, 26, 3829-3832.

16. (a) Shoji, T.; Ito, S.; Toyota, K.; Yasunami, M.; Morita, N.; Tetrahedron Lett. 2007, 48, 4999-5002; (b) Shoji, T.; Higashi, H.; Ito, S.; Toyota, K.; Yasunami, M.; Morita, N. Eur. J. Org. Chem. 2008, 1242-1252.

17. Jacquemin, D.; Lewalle, A.; Perpète, E. -A. Chem. Phys. Lett., 2008, 457, 91-95 